\title{
HISTOLOGIA DO INTESTINO DE TILÁPIA DO NILO ALIMENTADOS COM DIETAS CONTENDO DIFERENTES FONTES DE PROTEÍNA
}

\author{
HONORATO, Claucia Aparecida ${ }^{1}$ \\ ASSANO, Marcelo ${ }^{2}$ \\ CRUZ, Claudinei da ${ }^{3}$ \\ CARNEIRO, Dalton José ${ }^{4}$ \\ MACHADO, Márcia Rita Fernandes ${ }^{5}$
}

\begin{abstract}
RESUMO: O objetivo deste trabalho foi avaliar a histologia e a histoquímica do intestino anterior de tilápia do Nilo alimentadas com dietas contendo farinha de peixe ou silagem de peixe como fonte de proteína de origem animal. A espessura da vilosidade intestinal dos peixes alimentados com silagem fermentada de resíduo de tilápia foi influenciada pelos teores protéicos, independente das proporções de proteína de origem animal das dietas. Observouse que a variação da intensidade de secreção de glicoproteínas pelas células caliciformes está diretamente ligada com o tipo de dieta fornecida aos animais. O intestino médio de $O$. niloticus apresentou diferenças no padrão de secreção de muco glicoproteíco neutro, glicoproteínas ácidas e glicoconjugados, dependendo da origem da proteína e da porcentagem utilizada na dieta, demonstrando que esta espécie pode adaptar seu sistema de secreção para a proteção do aparelho digestório durante a absorção diferentes fontes protéicas.
\end{abstract}

Palavras Chaves: Oreochromis niloticus. Histologia do intestino. Silagem de peixe.

\section{HISTOLOGY OF INTESTINE THE TILÁPIA (OREOCHROMIS NILOTICUS) FEEDSTUFF SOURCES PROTEIN}

SUMMARY: This work was carried out evaluate the action of the fermented fish silage and fish meal in the middle $O$. niloticus intestine histochimical. The great epithelium intestinal was in the fishes fed with fish silage independent the animal origin protein proportions in diets. It was observed that the variation of the goblet cells secretion glicoproteic intensity is linked directly to the diet supplied to animals. The middle intestine of $O$. niloticus showed differences in the neutral mucus glicoproteic, acid glicoproteic and glicoconjugated secretion pattern, depending on the protein origin and the percentage used in the diet, demonstrating that this species can adapt its secretion system for the protection of the digesting apparatus during the absorption of different protein sources.

Keywords: Oreochromis niloticus. Histology of intestine. Fish silage.

\section{INTRODUÇÃO}

A tilápia do Nilo vem se destacando no cenário de produção de peixes de água doce, principalmente pelo ótimo desempenho e rusticidade, a facilidade de obtenção de alevinos, a aceitação no mercado e pela qualidade do seu filé (HAYASHI et al., 2002).

\footnotetext{
${ }^{1}$ Centro Universitário da Grande Dourados - UNIGRAN, Faculdade de Ciências Biológicas e da Saúde, e-mail clauciahonorato@yahoo.com.br

${ }^{2}$ Zootecnista, Mestre em Aquicultura, m.assano@ig.com.br

${ }^{3}$ Núcleo de Estudos e Pesquisas Ambientais em Matologia, Faculdade de Ciências Agrárias e Veterinárias, UNESP, Jaboticabal, SP, Brasil. cruz_claudinei@ hotmail.com

${ }^{4}$ Departamento de Zootecnia FCAV - UNESP, Laboratório de Nutrição de Organismos Aquáticos - Caunesp, Jaboticabal, SP, Brasil. daltoncj@caunesp.unesp.br

${ }^{5}$ Departamento de Morfologia e Fisiologia Animal da FCAV - UNESP, Jaboticabal, SP, Brasil. $\underline{\text { mrfmachd@fcav.unesp.br }}$
} 
No entanto, um dos entraves no sistema de produção de organismos aquáticos são os altos custos da alimentação, por isso são constantes as buscas por fontes alternativas de proteína de menores custos e de simples processamentos, que possam substituir a farinha de peixe, a principal fonte de proteína de origem animal utilizada na dieta para peixes (FERNANDES et al., 2001).

Dentre diversos substitutos destaca-se a silagem de peixe como fonte de proteína de origem animal produzido a partir de resíduos de peixe (VIDOTTI et al., 2002; HONORATO e CARNEIRO, 2003; CARVALHO et al., 2006) e a outra possível solução está em substituí-la por uma fonte de proteína de origem vegetal de boa qualidade como a soja integral (STECH, 1999; BOSCOLO et al., 2001, FURUYA et al., 2004).

O potencial da silagem de peixe como produto alternativo foi demonstrado para alevinos de pacu Piaractus mesopotamicus (VIDOTTI et al., 2002), piauçu Leporinus macrocephalus (FERNANDES et al., 2007), tilápia Oreochromis niloticus (CARVALHO et al., 2006; OLIVEIRA et al., 2006) sem qualquer prejuízo no seu desempenho produtivo.

A soja integral é uma alternativa como fonte de proteína e de grande potencial para peixes onívoro, apresentando bom desempenho (BOSCOLO et al., 2001). O potencial de utilização e as características nutricionais da soja foram demonstrados para alevinos de pacu (FERNANDES et al., 2000) e tilápia (FURUYA et al., 2004).

$\mathrm{Na}$ tentativa de aperfeiçoar o aproveitamento dos ingredientes ingeridos, os peixes apresentam capacidade de adaptação dos processos digestivos, tais como: perfil e secreção enzimáticos; absorção e transporte de nutrientes. O estudo morfológico revela o desempenho no processo digestivo, absortivo e metabólico dos diferentes animais (LUNDSTEDT et al., 2003), além de ser uma barreira seletiva que permite absorção de nutrientes e exclui muitas substâncias tóxicas (LIQUORI et al., 2007) e revela as diferentes adaptações do trato digestório em função a dieta ofertada (EVANS et al., 2005). Portanto, o estudo histológico é essencial para a tomada de decisão quanto ao tipo de fonte de alimento que podem ser recomendada para alimentação de peixes (ROMARHEIM et al., 2008).

Este trabalho teve como objetivo avaliar a resposta histológicas do intestino anterior de tilápia do Nilo quando submetidas a alimentação com dietas contendo silagem de peixe ou da soja integral como fontes alternativas de proteína à farinha de peixe.

\section{MATERIAL E MÉTODOS}

O experimento foi conduzido no Laboratório de Nutrição de Organismos Aquáticos do Centro de Aquicultura da UNESP e as análises histológicas no setor de técnicas morfológicas do Departamento de Morfologia e Fisiologia Animal da FCAV/UNESP, Campus de Jaboticabal.

Para a produção de silagem fermentada foi utilizado resíduos de filetagem de tilápia (cabeça, vísceras, restos de musculatura, espinhas, pele, escamas e nadadeiras), previamente moídos, adicionado $15 \%(\mathrm{p} / \mathrm{p})$ de melaço de cana-de-açúcar, $5 \%(\mathrm{p} / \mathrm{p})$ de Lactobacillus plantarum e 0,25\% (v/p) de ácido sórbico e armazenadas por 30 dias.

Para alimentação foram formuladas três dietas isoproteicas $(28 \% \mathrm{~PB})$ práticas extrusadas, utilizandose farinha de peixe, silagem de peixe ou soja integral, na porcentagem de $25 \%$ da fonte protéica (Tabela 1). $\mathrm{O}$ arraçoamento foi realizado à vontade duas vezes ao dia ad libitum, durante 180 dias. 
Tabela 1. Formulação e composição das dietas experimentais.

\begin{tabular}{|c|c|c|c|}
\hline \multirow[t]{2}{*}{ Ingredientes } & \multicolumn{3}{|c|}{ Fontes de proteína } \\
\hline & Farinha de peixe & Silagem de peixe & Soja integral \\
\hline Farinha de peixe & 13,0 & - & - \\
\hline Silagem de peixe & - & 15,5 & - \\
\hline Soja integral & - & - & 18,4 \\
\hline Milho & 10,0 & 13,2 & 11,5 \\
\hline Farelo de soja & 29,6 & 31,3 & 32,2 \\
\hline Farelo de arroz & 13,0 & 11,1 & 4,0 \\
\hline Farelo de trigo & 25,0 & 21,2 & 20,0 \\
\hline Quirera de arroz & 5,9 & 2,2 & 9,4 \\
\hline Óleo de soja & 2,3 & 1,5 & 0,3 \\
\hline Lisina & - & - & - \\
\hline Metionina & 0,1 & 0,1 & 0,2 \\
\hline Calcário & - & 1,5 & 1,5 \\
\hline Fosfato bicálcico & - & 1,1 & 1,3 \\
\hline Supl. Min. Vit. 1 & 1,3 & 1,3 & 1,3 \\
\hline \multicolumn{4}{|c|}{ Composição calculada $(\%)^{2}$} \\
\hline Matéria seca & 89,3 & 90,4 & 88,7 \\
\hline Proteína bruta & 28,0 & 28,0 & 28,0 \\
\hline Extrato etéreo & 6,6 & 6,6 & 6,4 \\
\hline ENN & 41,5 & 40,6 & 41,3 \\
\hline $\mathrm{EB}(\mathrm{Kcal} / \mathrm{kg})$ & 4042,0 & 3989,0 & 4015,0 \\
\hline
\end{tabular}

1 Composição do suplemento mineral e vitamínico: Ferro $15.000 \mathrm{mg}$, Cobre $5.000 \mathrm{mg}$, Iodo $500 \mathrm{mg}$, Manganês $17.000 \mathrm{mg}$, Zinco $12.000 \mathrm{mg}$, Selênio $70 \mathrm{mg}$, veículo $1000 \mathrm{~g}$, Vitamina A 12.000 UI, Vitamina D3 1500 UI, Vitamina E $50 \mathrm{mg}$, Vitamina K $4 \mathrm{mg}$, Vitamina B12 $7 \mathrm{mg}$, Vitamina B2 $7 \mathrm{mg}$, Ácido pantotênico $60 \mathrm{mg}$, Ácido nicotínico $120 \mathrm{mg}$, Cloreto de colina $600 \mathrm{mg}$, Metionina $700 \mathrm{mg}$, Antioxidante $500 \mathrm{mg}$, Veículo $1000 \mathrm{~g}$.

2 Composição calculada com base nos dados obtidos em análises realizadas no Laboratório de Nutrição de Organismos Aquáticos do CAUNESP, Jaboticabal, segundo AOAC (2000).

1 Mineral and vitamin supplement composition: Iron 15,000 mg, Copper 5,000 mg, Iodine 500 mg, Manganese 17,000 mg, Zinc 12,000 mg, Seleniun $70 \mathrm{mg}$, vehicle $1000 \mathrm{~g}$, Vitamin A 12,000 UI, Vitamin D3 1,500 UI, Vitamin E $50 \mathrm{mg}$, Vitamin $\mathrm{K} 4 \mathrm{mg}$, Vitamin B12 $7 \mathrm{mg}$, Vitamin B2 $7 \mathrm{mg}$, Panthotenic acid $60 \mathrm{mg}$, Nicotinic acid $120 \mathrm{mg}$, Choline chloride $600 \mathrm{mg}$, Methionine $700 \mathrm{mg}$, Antioxidant $500 \mathrm{mg}$, Vehicle $1000 \mathrm{~g}$.

2 Calculated composition based on the analyses performed at the Aquatic Organisms Nutrition Lab of CAUNESP, Jaboticabal, according to AOAC (2000).

Foram utilizados 1000 juvenis de tilápia do Nilo revertidos, na densidade de um peixe $/ \mathrm{m}^{2}$, sendo classificados em dois blocos com peso médio inicial de $60 \pm 5 \mathrm{~g}$ e $80 \pm 5 \mathrm{~g}$. Para o ensaio foram utilizados 18 viveiros de $10 \mathrm{~m}$ x $5 \mathrm{~m}$ com profundidade em torno de $1,5 \mathrm{~m}$, com paredes revestidas de alvenaria e fundo de terra.

Durante o experimento a temperatura foi monitorada diariamente, utilizando um termômetro de máxima e mínima instalado a um metro de profundidade em cada viveiro experimental; as variáveis 
físico-químicas da água foram analisadas mensalmente, sendo monitoradas sempre às sete horas da manhã, na saída de água de cada viveiro.

No início e ao final do experimento foi realizada uma biometria, com amostragens de $20 \%$ dos peixes, quando foi registrado o peso de cada indivíduo. A avaliação do desempenho foi através do ganho em peso $(\mathrm{GP})=($ peso final - peso inicial $)$.

No final do período experimental, cinco peixes de cada tratamento foram anestesiados em benzocaína $(100 \mathrm{mg} / \mathrm{L})$ até completa perda dos sentidos para a biometria e abate em gelo. Foi separado fragmentos de intestino anterior para as análises histológicas. As amostras foram fixadas em solução de Bouin, por 24horas. Após a fixação, procedeu-se à lavagem em álcool $70 \%$ para desidratação em série alcoólica crescente, diafanização em série de xilóis, inclusão em Histosec e cortados em espessura variando entre 5 a $7 \mu \mathrm{m}$ de espessura. Para cada tratamento (dieta experimental) foi confeccionada três lâminas por peixe com total de 27 lâminas por tratamento.

A coloração das lâminas foi realizada pela técnica Hematoxilina - Eosina. Para realização da histoquímica utilizou-se os métodos de PAS/H (Ácido periódico de Shiff). Foi realizada a análise de sete secções por lâmina. O material foi analisado e fotodocumentado em fotomicroscópio Axioskop- Zeiss. Foi realizada a comparação visual da altura das vilosidades intestinal dos peixes submetidos a distintas dietas experimentais. As comparações foram realizadas agrupando os tratamentos em três classes de altura denominados de pequenas, mediana e alta.

$\mathrm{O}$ experimento foi conduzido em delineamento inteiramente casualizado (DIC), com três tratamentos correspondendo as fontes de proteína (farinha de peixe, soja integral ou silagem de peixe) com duas repetições. Quando a análise de variância mostrou diferenças significativas entre tratamentos $(\mathrm{P}<0,05)$, as médias foram comparadas pelo teste Tukey, realizados no Statistical Analysis System (SAS Intitule Inc., version 6.12, 1999).

\section{RESULTADOS}

As médias dos parâmetros físico-químicos da qualidade da água durante todo o período experimental foram: oxigênio dissolvido de 4,38 $\pm 0,92 \mathrm{mg} \mathrm{O}^{2} / \mathrm{L}$, temperatura entre 18 e $33^{\circ} \mathrm{C}, \mathrm{pH}$ de 8,2 $\pm 0,35$, alcalinidade de 28,7 $\pm 6,5 \mathrm{mg} / \mathrm{L}$ e amônia de $0,1 \pm 0,05 \mathrm{mg} / \mathrm{L}$. Estes valores mantiveram-se estáveis durante o experimento, apresentando-se dentro dos limites recomendados para peixes de águas tropicais (KUBITZA, 2003).

O uso de ingredientes alternativos a farinha de peixe na aquicultura vem sendo testadas para várias espécies de peixe (BOSCOLO et al., 2001; VIDOTTI et al., 2002; HONORATO e CARNEIRO, 2003; CARVALHO et al., 2006) revelando o potencial de substituição sem prejuízo para o desenvolvimento dos peixes. A utilização de silagem co-seca na alimentação de pacu (VIDOTTI et al., 2002) e piavuçu (FERNADES et al., 2007) assim como a isenção de fontes de proteína de origem animal na alimentação de curimbatá Prochilodus lineatus (GALDIOLI et al., 2000) e de pacu (FERNANDES et al., 2000) não promoveu prejuízo ao crescimento.

No entanto, o trato digestório dos animais tende a se modificar conforme a alimentação ofertada. Portanto estudo da morfologia intestinal podem indicar a adaptação dos peixes a alimentação a longo prazo (HONORATO et al., 2011). O intestino anterior de tilápia do Nilo caracteriza-se por apresentar quatro camadas: a mucosa, a submucosa, a muscular e a serosa. A camada mucosa está constituída por epitélio cilíndrico simples com borda em escova e células caliciformes, com lâmina própria contendo linfócitos intra-epiteliais; a submucosa formada por células, fibras colágenas e vasos sanguíneos; a camada 
muscular de músculo liso em disposição circular e externamente à camada serosa, caracterizada por tecido conjuntivo e células pavimentosas. Estas estruturas não apresentaram diferença na tilápia do Nilo submetidas às dietas experimentais (Figura 2).

Figura 2. Foto micrografia de intestino anterior de juvenis de tilápia do Nilo (Oreochromis niloticus)

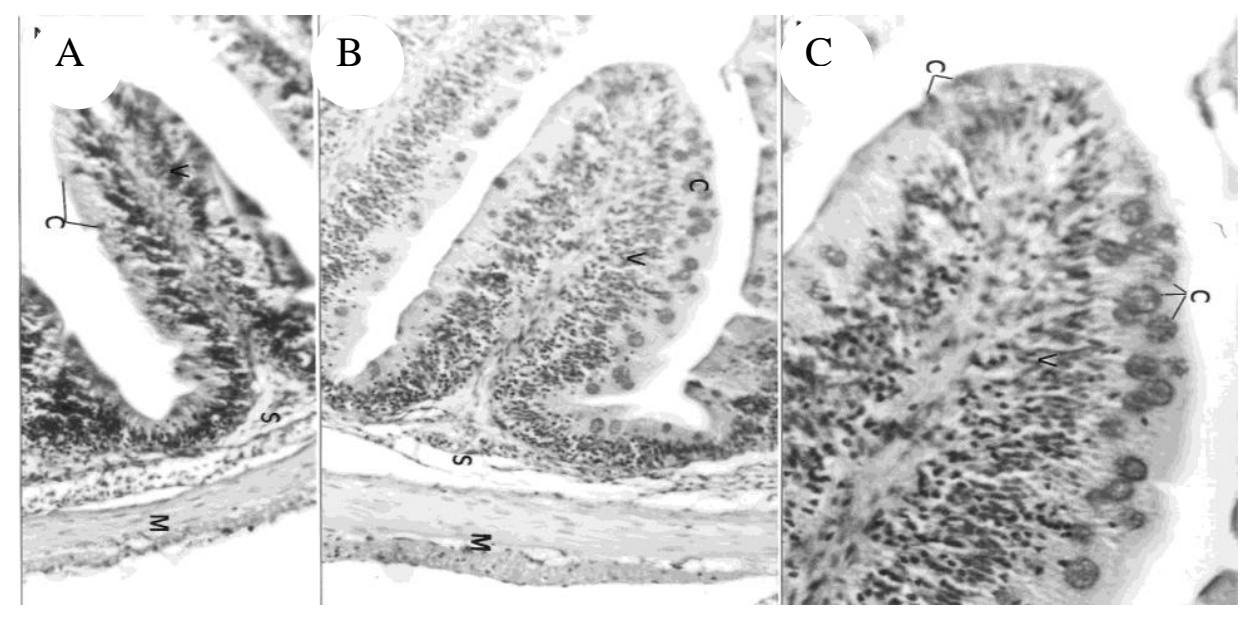

A. Fotomicrografia do intestino anterior de tilápia demonstrando a vilosidade intestinal (V), células caliciformes (C), submucosa (S) e túnica muscular (M). PAS/H. 200x. Dietas com farinha de peixe; B. Fotomicrografia do intestino anterior de tilápia demonstrando a vilosidade intestinal (V), células caliciformes $(\mathrm{C})$, submucosa $(\mathrm{S})$ e túnica muscular (M). PAS/H. 200x. Dietas com silagem de peixe; C. Detalhe de uma vilosidade intestinal (V) células caliciformes (C) do intestino anterior. PAS/H. 400x. Dietas com soja integral

A fonte de proteína utilizada nas dietas para tilápia d Nilo alteraram a altura da vilosidade intestinal e também a ocorrência de células caliciformes (Figura 3). Os cortes histológicos revelaram que a altura das vilosidades intestinais foi responsiva a fonte de proteína utilizada. $\mathrm{O}$ uso de silagem de peixe na laimentação de tilápia resultou em altura de vilosidade intestinais classificadas como alta. A altura das vilosidades dos peixes submetidos a alimentação com farinha de peixe e com soja integral foram semelhantes e classificadas como medianas (Tabela 2). Honorato et al. (2011) relatam que o uso da silagem de peixe em dietas para tilápia resultam em aumento no tamanho das vilosidades intestinais. A adaptação da altura da vilosidade intestinal de peixes em relação a dieta ofertada já foi descrito para Rachycentron canadum (ROMARHEIM et al., 2008) Onchorinchus mykiss e do Piaractus mesopotamicus (OSTASZEWSKA et al., 2005).

Tabela 2. Altura das vilosidades intestinal e histoquímica das células caliciformes do intestino médio de juvenis de tilápia do Nilo (Oreochromis niloticus) submetidos às dietas com diferentes fontes de proteína.

\begin{tabular}{|c|c|c|c|c|c|c|c|}
\hline \multirow[t]{2}{*}{ Fontes de proteína } & \multirow[t]{2}{*}{ Altura. } & \multicolumn{3}{|c|}{ AB/PAS } & \multicolumn{3}{|c|}{ PAS } \\
\hline & & Neutra & Ácida & Conjugada & Neutra & Ácida & Conjugada \\
\hline Farinha de peixe & $* *$ & ++ & - & ++ & ++ & - & - \\
\hline Soja integral & $* *$ & + & - & + & + & - & - \\
\hline Silagem de peixe & $* * *$ & + & + & + & ++ & - & - \\
\hline
\end{tabular}

Altura das vilosidades intestinal: * (pequena), ** (mediana) e *** (alta)

Intensidade da reação positiva: (+) fraca; $(++)$ intermediária; $(+++)$ forte; (-) sem reação 
A mucosa exibiu um epitélio prismático simples composto por enterócitos entremeados por células caliciformes PAS (positivo) e PAS/AB (positivo), indicando a secreção de glicoproteínas neutras e glicoproteínas ácidas sulfatadas e glicoconjugadas. Apenas os peixes alimentados com a dieta contendo silagem de peixe apresentaram células caliciformes com secreção glicoproteínas ácidas sulfatadas (AB/PAS). A secreção de glicoproteías neutras e glicoconjugadas (AB/PAS) apresentaram o mesmo padrão para os peixes alimentados com soja integral e silagem de peixe. Observou-se que a intensidade de reação da secreção glicoconjugado (AB/PAS) nos animais alimentados com dietas contendo farinha de peixe foi superior quando comparada aos demais tratamentos (Tabela 2).

As classificações das alturas das vilosidades intestinais (pequena, mediana e alta) estão apresentadas na Tabela 2. A utilização de farinha de peixe como fonte de proteína diminui a incidência no número de células caliciforme presentes no intestino anterior dos peixes (Figura 3B). A utilização de silagem de peixe (Figura $3 \mathrm{E}$ ) como fonte de proteína resultou em aumento no tamanho das vilosidades intestinais quando comparados com o uso da farinha de peixe (Figura 3C) e do farelo de soja (Figura 3A).

A presença e a quantidade de células caliciformes estão relacionadas com a proteção da estrutura intestinal (TIBBETS, 1997). Os tipos de secreção destas células possam está associada ao tipo de alimento (HONORATO et al., 2011). Em um estudo com truta arco-íris (Salmo gairdneri) alimnetadas com silagem de peixe observou-se que este alimento foi capaz de alterar a estrutura de digestão e absorção (RUNGRUANGASK e UTNE, 1981).

\section{Figura 3.}

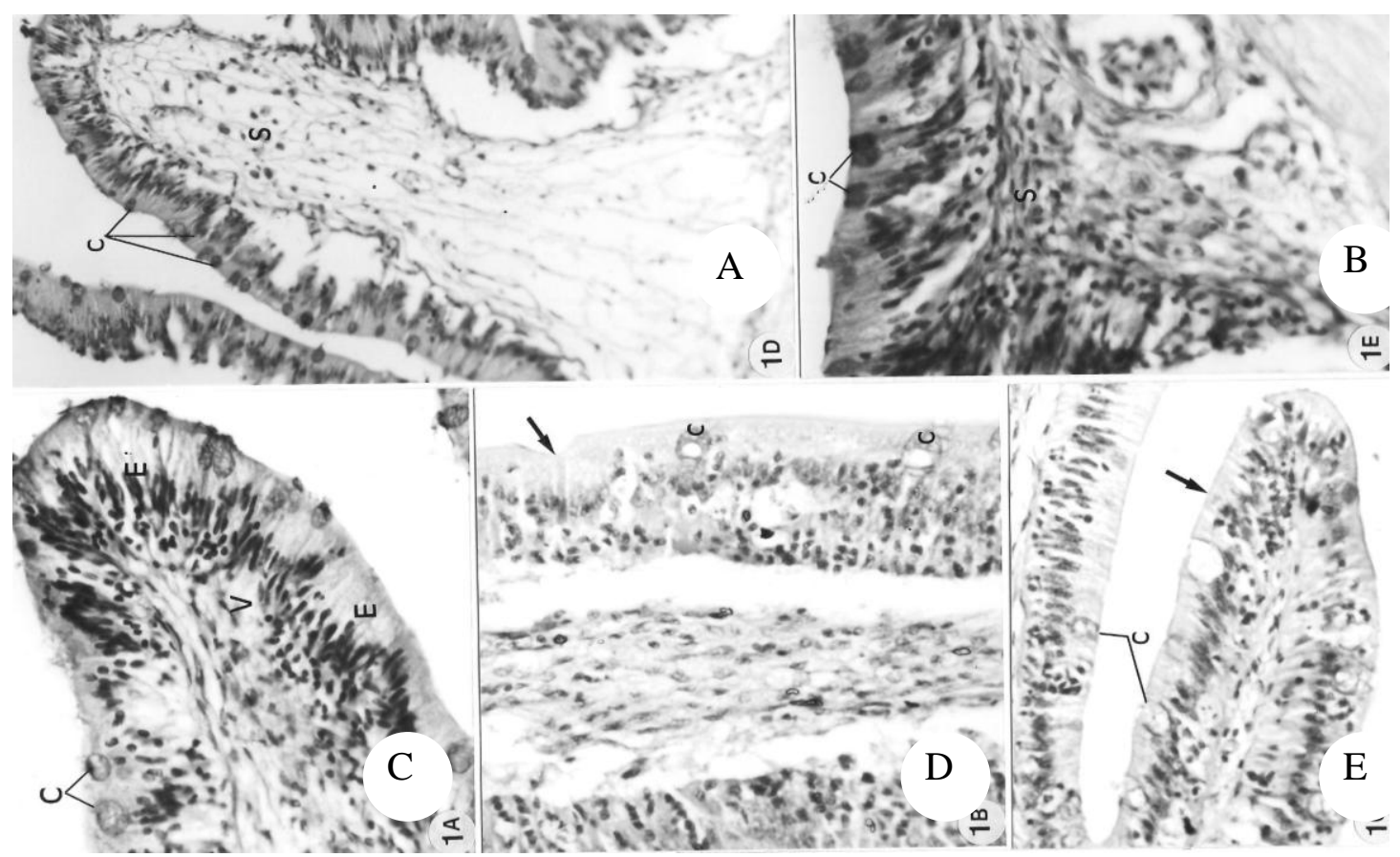

A. Fotomicrografia do intestino posterior de tilápia mostrando células caliciformes (C) e submucosa (S). PAS/H. 200x. Dieta com soja integral. B Fotomicrografia do intestino posterior de tilápia mostrando células caliciformes (C) e submucosa (S). PAS/H. 200x. Tratamento com silagem de peixe com. C. Fotomicrografia do intestino anterior de tilápia mostrando a vilosidade intestinal (V), células caliciformes (C), enterócitos (E). PAS/H. 400x. Dieta com farinha de peixe; D. Fotomicrografia do intestino anterior de tilápia evidenciando a borda em escova (B) (PAS positiva com fraca intensidade de reação) e células caliciformes (C). PAS/H. 400x. Dieta com silagem de peixe; E. Fotomicrografia do intestino médio de tilápia evidenciando a borda em escova (B) (PAS positiva com fraca intensidade de reação) e células caliciformes (C). PAS/H. 400x. Dieta com silagem de peixe. 


\section{CONCLUSÃO}

Os resultados indicam que a fonte de proteína provoca alterações na estrutura morfológica do intestino de tilápia do Nilo.

A utilização da silagem de peixe e da soja integral apresenta potencial para substituir a farinha de peixe, em dietas práticas sem qualquer prejuízo a tilápia do Nilo.

\section{REFERÊNCIAS}

A. O. A. C. ASSOCIATION OF OFFICIAL AGRICULTURAL CHEMISTS. A. O. A. C. Official methods of analysis of the association of Official Agricultural Chemists. 15. ed. Arlington, 2000. $1298 \mathrm{p}$.

BENGSTON, D.A. A comprehensive program for the evaluation of artificial diets. Journal World Aquaculture Society, v.24, p. 285-293, 1993.

BOSCOLO, W.R. et al. Desempenho e características de carcaça de machos revertidos de tilápia do Nilo (Oreochromis niloticus), linhagem tailandesa e comum, nas fases iniciais e crescimento. Revista

Brasileira de Zootecnia, v. 30, n. 5, p. 1391-1396, 2001.

BOSCOLO, W.R. et al. Farinha de peixe, carne e ossos, víceras e crisálida como atractantes em dietas para alevinos de tilápia do Nilo (Oreochromis niloticus). Revista Brasileira de Zootecnia, v. 30, n. 5, p. 1397-1420, 2001.

BUDDINGTON, R.K.; KROGDAHAL, ̊̊ ; BAKKE-MCKELLEP, A.M. The intestine of carnivorous fish; structure and functions and the relations with diet. Acta Physiology Scandinavica, v. 161, p. 67-80, 1997.

CARVALHO, G. G. P. et al. Silagem de resíduo de peixes em dietas para alevinos de tilápia-do-Nilo. Revista Brasileira de Zootecnia, v.35, n.1, p.126-130, 2006.

DOMENEGHINI C. et al. Histochemical analysis of glycoconjugate secretion in the alimentary canal of Anguilla anguilla L. Acta Histochemical, v.106, p.477-487, 2005.

ESPE, M.; RAA, J.; NJAA, L.R. Nutritional value of stored fish silage as a protein source for young rats. Journal of Science Food and Agriculture, v.49, p.259-70, 1989.

EVANS, J.J. et al. No apparent differences in intestinal histology of channel catfish (Ictalurus punctatus) fed heat-treated and non-heat-treated raw soybean meal. Aquaculture Nutrition, v. 11, p. 123-129, 2005

FAGBENRO, O.A.; JAUNCEY, K.; HAYLOR, G. Nutritive value of diets containing dried lactic acid fermented fish silage and soybean meal for juvenile Oreochromis niloticus and Clarias garipinus. Aquatic Living Resource, v.7, p. 79-85, 1994.

FERNANDES, J.B.K. et al. Silagem ácida de resíduos de filetagem de tilápias em rações de juvenis de piauçu (Leporinus macrocephalus). Acta Scientiarum Animal Sciences, v. 29, n. 3, p. 339-344, 2007

FERNANDES, J.B.K.; CARNEIRO, D.J.; SAKOMURA, N.K. Fontes e níveis de proteína bruta em dietas para alevinos de pacu (Piaractus mesopotamicus). Revista Brasileira de Zootecnia, v.29, n.3, p.646-653, 2000. 
FERNANDES, J.B.K.; CARNEIRO, D.J.; SAKOMURA, N.K. Fontes e níveis de proteína bruta em dietas para juvenis de pacu (Piaractus mesopotamicus). Revista Brasileira de Zootecnia, v.30, n.3, p. 617-626, 2001.

GALDIOLI, E.M. et al. Effect of different proteic sources on curimba Prochilodus lineatus V. fingerlings nourishment. Acta Scientiarum, v. 22, n. 2, p. 471-477, 2000.

HANSEN, A.C.et al. the inclusion of plant protein in cod diets, its effects on macronutrient digestibility, gut and liver histology and heat shock protein transcription. Aquaculture Research, v.37, p.773-784, 2006 ,

HAYASHI C.et al. Exigência de proteína digestível para larvas de tilápia do Nilo (Oreochromis niloticus), durante a reversão sexual. Revista Brasileira de Zootecnia, v.31, n.2, p.823-828, 2002.

HONORATO, C.A.; CARNEIRO, D.J. Corporal composition of Nile tilapia fingerling Oreochromis niloticus fed with diets containing both different sources and protein levels and proportions of animal protein. In: WORLD AQUACULTURE, 2003, Salvador. Anais. Salvador: World Aquaculture, 2003. v. 2. p. 354.

KOPOOR, B. G.; SMITH, H.; VERIGHINA, I.A. The alimentary canal and digestion in teleostets. Advanced Marine Biology, v.13, p.109- 139, 1975.

KUBITZA, F. Qualidade da água no cultivo de peixes e camarões. Piracicaba: Degaspari, 2003.

KUPERMAN, B.I.; KUZ'MINA, V.V. The structure of the intestinal epithelium in fish with different types of feeding. Journal Fish Biological, v. 44, p. 181-193, 1994.

LIQUORI, G.E.et al. Glycoconjugate histochemistry of the digestive tract of Triturus carnifex (Amphibia, Caudata). Journal Morphology Histology, v.38, p. 191-199, 2007.

LUNDSTEDT, L.M. Aspectos adaptativos dos processos digestivo e metabólico de juvenis de pintado (Pseudoplatystoma corruscans) arraçoados com diferentes níveis de proteína e energia. 2003. 140f. Tese (Doutorado em Genética e Evolução). Universidade Federal de São Carlos. 2003.

OLIVEIRA, M. M.et al. Digestibilidade e desempenho de alevinos de tilápia do Nilo (Oreochromis niloticus) alimentados com dietas contendo diferentes níveis de silagem ácida de pescado. Ciência Agrotecnologia, v. 30, n. 6, p. 1196-1204, 2006.

OSTASZEWSKA, T.et al. Growth and morphological changes in the digestive tract of rainbow trout (Oncorhynchus mykiss) and pacu (Piaractus mesopotamicus) due to casein replacement with soybean proteins. Aquaculture, v. 245, p. 273-286, 2005.

REOPEREZ, J.et al. Efecto de la alimentación com harina de soja sometida a distintos tratamientos sobre el crescimento y morfología intestinal del lechon. Archivos de Zootecnia, v. 42, p. 125 - 135, 1993.

ROMARHEIM, O.H.et al. Growth and intestinal morphology in cobia (Rachycentron canadum) fed extruded diets with two types of soybean meal partly replacing fish meal. Aquaculture Nutrition, v. 14, n 2, p. 174-180, 2008.

RUNGRUANGASK, K., UTNE, F. Effect of different acidified wet feeds on protease activities in the digestive tract and on the growth rate of rainbow trout (Salmo gairdneri Richarson). Aquaculture, v.22, p.67-79, 1981.

SANTOS, C.M.et al. Histologia e caracterização histoquímica do tubo gastrintestinal de Pimelodus maculatus (Pimelodidae, Siluriformes) no reservatório de Funil. Rio de Janeiro, n. 4, p. 411-417, 2007. (Série Zoologia, v. 97). 
SCHUCHARDT, D.et al.. Effects of different dietary protein and lipid levels on growth feed utilization and body composition of red porgy (Pagrus pagrus) fingerlings. Aquaculture Nutrition, v. 14, p. 1-9, 2008.

SECCO, E. M., STÉFANI, M. V., VIDOTTI, R. M. Substituição da farinha de peixe pela silagem de peixe na alimentação de girinos de rã touro (Rana catesbiana). Ciência Rural, v.32, n.3, p. 505-509, 2002.

STATICAL ANALISYS SYSTEM SAS. Institute, SAS/STAT SAS/STAT. User's guide: statistic: Versão 6.08.4. ed. Cary, 1999.

STATICAL ANALISYS SYSTEM SAS. Institute, SAS/STAT SAS/STAT. User's guide: statistic: Versão 6.08.4. ed. Cary, 1999.

STECH, M.R. Utilização de soja integral processada em dietas para o crescimento de pacu Piaractus mesopotamicus (Holmberg, 1887), 1999. 90f. Dissertação (Mestrado em Produção Animal) -

Universidade Estadual Paulista. Jaboticabal.

TAKASHIMA, F.; HIBIYA, T. An atlas of fish Histology: normal and pathological features. 2.ed. Tokio: Kondansha Ltda; Stuttgart, New York: Fisher. 1995. 195p.

TIBBETTS, I.R. The distribution and function of mucous cells and their secretions in the alimentary tract of Arrhamphus sclerolepis krefftii. Journal of Fish Biology, v. 50, p. 809-820, 1997.

VIDOTTI, R. M., VIEGAS, E.M.M., CARNEIRO, D.J. Amino acid composition of processed fish silage using different raw materials. Animal Feed Science and Technology, v. 105, p. 199-204, 2003.

VIDOTTI, R. M.; CARNEIRO, D.J.; VIEGAS, E.M.M. Growth rate of pacu, Piaractus mesopotamicus, fingerlings fed diets containig co-dried ish silage as replacement of fish meal. Journal of Applied Aquaculture, v.12, n. 4, p. 77-88, 2002.

WASSEF, E.A.; WAHBY, O. M.; SAKR, E. M. Effect of dietary vegetable oils on health and liver histology of gilthead seabream (Sparus aurata) growers. Aquaculture Research, v 38, p. 852-861, 2007. 
